\title{
Effects of indacaterol versus tiotropium on respiratory mechanics assessed by the forced oscillation technique in patients with chronic obstructive pulmonary disease
}

\author{
This article was published in the following Dove Press journal: \\ International Journal of COPD \\ 17 June 2015 \\ Number of times this article has been viewed
}

\author{
Naoki Inui ${ }^{1,2}$ \\ Sayomi Matsushima' \\ Shinpei Kato' \\ Hideki Yasui' \\ Masato Kono' \\ Tomoyuki Fujisawa' \\ Noriyuki Enomoto' \\ Yutaro Nakamura' \\ Mikio Toyoshima ${ }^{3}$ \\ Takafumi Suda' \\ 'Second Division, Department \\ of Internal Medicine, ${ }^{2}$ Department \\ of Clinical Pharmacology and \\ Therapeutics, Hamamatsu University \\ School of Medicine, Handayama, \\ Hamamatsu, Japan; ${ }^{3}$ Department \\ of Respiratory Medicine, Hamamatsu \\ Rosai Hospital, Shougen-cho, \\ Hamamatsu, Japan
}

\begin{abstract}
The forced oscillation technique (FOT) can measure respiratory mechanics and has attracted attention in chronic obstructive pulmonary disease (COPD). We aimed to evaluate the effects of only indacaterol and tiotropium monotherapies on airflow limitation and respiratory impedance. Pulmonary function tests, COPD assessment test (CAT), and multifrequency FOT with MostGraph-01 were performed at the beginning and after 8 weeks of treatment with indacaterol or tiotropium. The resistance index, resistance at $5 \mathrm{~Hz}$ (R5), resistance at $20 \mathrm{~Hz}$ (R20), reactance index, reactance at $5 \mathrm{~Hz}$ (X5), resonant frequency (Fres), and low-frequency reactance area (ALX) were determined at whole-breath, inspiratory, and expiratory phases. Eighty-two patients (mean age: 73 years; mean forced expiratory volume in 1 second $\left(\mathrm{FEV}_{1}\right)$ : $61.6 \% \pm 19.0 \%$ predicted) were randomized to indacaterol or tiotropium treatment. Both bronchodilators improved airflow limitation, with mean trough improvements in FEV of $165 \mathrm{~mL}$ and $80 \mathrm{~mL}$ in the indacaterol and tiotropium groups, respectively. The CAT score decreased in the indacaterol group $(P<0.001 ; 11.2 \pm 6.6$ to $7.5 \pm 5.6)$. Compared with tiotropium, indacaterol significantly improved $\mathrm{FEV}_{1}$, percent predicted $\mathrm{FEV}_{1}$, and CAT score $(P=0.042, P=0.008$, and $P=0.027$, respectively). For respiratory impedance, indacaterol and tiotropium changed R5, X5, Fres, and ALX at whole-breath, inspiratory, and expiratory phases. In the indacaterol group, the changes in R5, R5-R20, X5, Fres, and ALX were significantly correlated with the changes in $\mathrm{FEV}_{1}$. The use of the FOT may enable the evaluation of the effects of bronchodilators in addition to $\mathrm{FEV}_{1}$-indicated therapeutic effects in COPD.
\end{abstract}

Keywords: chronic obstructive pulmonary disease, forced oscillation technique, indacaterol, monotherapy, MostGraph-01, reactance, resistance, tiotropium

\section{Introduction}

Chronic obstructive pulmonary disease (COPD) is an airway disease characterized by persistent, incompletely reversible, and commonly progressive airflow limitation. ${ }^{1,2}$ The forced expiratory volume in 1 second $\left(\mathrm{FEV}_{1}\right)$ obtained by spirometry evaluates the presence of airflow limitation and is currently used to diagnose and assess the severity of airflow limitation in COPD. ${ }^{1,2}$ However, COPD is a complicated disorder with various pathophysiological changes ${ }^{2,3}$ and the $\mathrm{FEV}_{1}$ value has limits to fully represent the disease burden and diversity. ${ }^{3}$ Other indices and methods, such as exacerbation rate, quality of life, symptoms assessed by the St George's Respiratory Questionnaire, modified Medical Research Council breathlessness scale, and COPD assessment test (CAT), and comorbidities, can be used for assessment of COPD. ${ }^{1,3}$
Correspondence: Naoki Inui Department of Internal Medicine, Hamamatsu University School of Medicine, I-20-I Handayama, Hamamatsu 43I-3192, Japan

Tel +8I 534352263

Fax +8I 534352386

Email inui@hama-med.ac.jp 
For some years, the forced oscillation technique (FOT) has attracted attention in obstructive pulmonary diseases, asthma, and COPD. ${ }^{46}$ The FOT can measure respiratory mechanics during tidal breathing in an effort-independent manner with little cooperation by the subject. It can reflect the daily respiratory physiology and measure changes in response to therapy very sensitively. ${ }^{4,7,8}$ At present, two commercial multifrequency FOT devices, the impulse oscillation system ${ }^{9}$ and MostGraph-01 (Chest M.I., Co., Ltd., Tokyo, Japan), ${ }^{10}$ are available in Japan.

At present, inhaled anticholinergic and $\beta_{2}$-agonist bronchodilators are central to the pharmacological interventions for COPD. ${ }^{2}$ Current guidelines recommend a choice of bronchodilators depending on the availability, clinical response of symptom relief, and adverse effects, ${ }^{1}$ and monotherapy with long-acting bronchodilators is used as maintenance therapy for patients with mild-to-severe COPD. Tiotropium is a long-acting muscarinic antagonist with a 24 -hour persistent bronchodilator effect and is given once daily. ${ }^{11}$ It has been reported to improve airflow limitation, symptoms, and quality of life, and reduce exacerbation and hospitalization. ${ }^{12}$ Based on abundant evidence, tiotropium has been widely used as a first-line maintenance therapy. $\beta_{2}$-agonists comprise another class of bronchodilators that affect $\beta_{2}$ receptors in bronchial smooth muscle and dilate the bronchi. Among the long-acting $\beta_{2}$-agonists (LABAs), salmeterol and formoterol have an approximately 12-hour effect and require twice-daily administration..$^{13}$ Indacaterol is a novel LABA characterized by a 24-hour persistent bronchodilator effect. In addition, indacaterol has a rapid bronchodilator effect and was reported to increase $\mathrm{FEV}_{1}$ even at 5 minutes postdose. ${ }^{14}$ The relative potency of indacaterol on trough $\mathrm{FEV}_{1}$ was reported to be $60-100 \mathrm{~mL}$ greater than the trough $\mathrm{FEV}_{1}$ measured at 12 hours after dosing with salmeterol or formoterol. ${ }^{15}$

The present study compares tiotropium and indacaterol monotherapies in COPD patients. We evaluated the effects of these monotherapies on airflow limitation and respiratory impedance, assuming that these bronchodilators would have different properties on the large and the small airways. Although the FOT has already been used to assess COPD, ${ }^{5,6,16-20}$ to our knowledge, no previous studies have analyzed the therapeutic effects of indacaterol using this method. In addition, we investigated the relationships between the changes in $\mathrm{FEV}_{1}$ and FOT parameters.

\section{Methods}

\section{Patients}

Patients with COPD who were aged $\geq 40$ years, had $\geq 10$ pack-years of smoking history, and had airflow limitation classified as Global Initiative for Chronic Obstructive Lung
Disease (GOLD) I-III ( $\mathrm{FEV}_{1} 30 \%-80 \%$ of predicted value) were eligible for inclusion. The diagnosis and classification of COPD were performed according to the GOLD classification, which is based on the post-bronchodilator baseline lung function. ${ }^{1}$ Patients were excluded from the study if they met the following exclusion criteria: two or more courses of oral corticosteroid or antibiotics in the previous 6 months; admission to hospital because of exacerbation in the previous 6 months; presence of large bulla or pneumothorax; severe chronic heart failure; or use of long-term oxygen therapy. We also excluded patients who exhibited significant bronchodilator reversibility (improvement of $\mathrm{FEV}_{1}$ after inhalation of a short-acting bronchodilator of greater than $200 \mathrm{~mL}$ and $12 \%$ of the pre-bronchodilator $\mathrm{FEV}_{1}$ ) or had symptoms that were compatible with bronchial asthma.

\section{Study design}

This study was an open-label, randomized trial conducted in accordance with the Declaration of Helsinki. The study protocol was approved by the Institutional Review Board of each participating institution. All patients provided written informed consent. The trial was registered with the University Hospital Medical Information Network (UMIN) Clinical Trial Registry (UMIN ID 000009951).

After the initial evaluation, the eligible patients completed a $>2$-week baseline run-in period in which any bronchodilators including tiotropium (SPIRIVA HandiHaler; Boehringer Ingelheim, Ingelheim, Germany), regularly inhaled LABAs, inhaled corticosteroid, LABA/inhaled corticosteroid combinations, methylxanthine, and mucolytic agents were withdrawn. Following the run-in period, the patients were randomly assigned to a group receiving tiotropium (tiotropium treatment group) or a group receiving indacaterol (indacaterol treatment group) using a computer program. In the indacaterol treatment group, patients received indacaterol $150 \mu \mathrm{g}$ once daily for 8 weeks using a Breezhaler device. In the tiotropium treatment group, tiotropium $18 \mu \mathrm{g}$ was administered once daily for 8 weeks using a HandiHaler device. A rescue inhaled short-acting $\beta_{2}$-agonist was used on demand to control symptoms throughout the study. Pulmonary function tests and the FOT were performed at the beginning and after 8 weeks of treatment. The $\mathrm{FEV}_{1}$, forced vital capacity (FVC), maximum midexpiratory flow rate (MMF), maximum expiratory flow rate at $50 \% \mathrm{FVC}\left(\mathrm{V}_{50}\right)$ and $25 \% \mathrm{FVC}$ $\left(\mathrm{V}_{25}\right)$, and the inspiratory capacity were measured using an electric spirometer (Autospirometer System 7; Minato Medical Science Co., Ltd., Osaka, Japan). FVC and $\mathrm{FEV}_{1}$ were expressed as percentages of predicted values according to the prediction equations of the Japanese Respiratory Society. ${ }^{21}$ 
All measurements were taken before inhalation of the drugs in the morning and at least 1 hour after drinking and eating. Short-acting $\beta_{2}$-agonists were not used for more than 12 hours before these tests in all cases. In addition, symptoms and health status were assessed using the CAT.

\section{Measurement of respiratory impedance}

Respiratory impedance was measured using a commercially available multifrequency FOT device (MostGraph-01) as previously reported, ${ }^{6,22,23}$ following standard recommendations. ${ }^{4}$ Briefly, impulse oscillatory signals generated by a loud speaker at 0.25 -second intervals were applied to the respiratory system through a mouthpiece during tidal breathing at rest. Mouth pressure and flow signals were measured and calculated, and the resistance and reactance properties against the oscillatory frequency were obtained. The FOT was performed before pulmonary function tests. During measurements, the subjects supported their cheeks firmly while sitting with their neck in a comfortable neutral posture. We evaluated the resistance at $5 \mathrm{~Hz}$ (R5), resistance at $20 \mathrm{~Hz}(\mathrm{R} 20)$, reactance at $5 \mathrm{~Hz}(\mathrm{X} 5)$, resonant frequency (Fres) where the reactance crosses zero and the elastic and inertial forces are equal in magnitude and opposite in sign, and low-frequency reactance area (ALX), which is the integral of reactance from $5 \mathrm{~Hz}$ to Fres. Each oscillatory index was expressed at whole-breath, inspiratory, and expiratory phases. The difference $(\Delta)$ in each oscillatory index between the expiratory and inspiratory phases was calculated.

\section{Statistical analysis}

The efficacies of indacaterol and tiotropium were assessed by the changes in the pulmonary function, FOT, and CAT. All values were analyzed using SPSS Statistics (version 21.0; IBM Corporation, Armonk, NY, USA). The Wilcoxon test was used for continuous variables and the chi-square test was used for categorized groups. Differences between the treatment groups and between the baseline and posttreatment values were analyzed by repeated-measures analysis of variance. Correlations between different parameters were evaluated using the Spearman's rank correlation coefficient test. Values of $P<0.05$ were considered to indicate significant differences. All data are described as mean \pm standard deviation, unless otherwise indicated.

\section{Results}

\section{Characteristics of the COPD patients}

We recruited 82 patients with COPD (Table 1). The median age was 73 years (range: $52-89$ years). All patients were
Table I Characteristics of patients with COPD

\begin{tabular}{|c|c|c|}
\hline & $\begin{array}{l}\text { Indacaterol } \\
\text { treatment } \\
\text { group }(n=4 I)\end{array}$ & $\begin{array}{l}\text { Tiotropium } \\
\text { treatment } \\
\text { group }(n=4 I)\end{array}$ \\
\hline Age, years & $72.2(8.4)$ & $72.8(9.0)$ \\
\hline \multicolumn{3}{|l|}{ Sex } \\
\hline Male & $39(95.1)$ & $4 I(100)$ \\
\hline Female & $2(4.9)$ & $0(0)$ \\
\hline \multicolumn{3}{|l|}{ Smoking status } \\
\hline Former smoker & $33(80.5)$ & $37(90.2)$ \\
\hline Current smoker & $8(19.5)$ & $4(9.8)$ \\
\hline Pack-years & $61.8(53.1)$ & $58.7(31.1)$ \\
\hline \multicolumn{3}{|l|}{ GOLD criteria } \\
\hline $\mathrm{I} / \mathrm{II} / \mathrm{III} / \mathrm{IV}$ & $9 / 19 / 13 / 0$ & $11 / 15 / 15 / 0$ \\
\hline Body mass index $\left(\mathrm{kg} / \mathrm{m}^{2}\right)$ & $22.2(3.9)$ & $22.7(3.1)$ \\
\hline \multicolumn{3}{|l|}{ Pulmonary function tests } \\
\hline FVC (L) & $2.90(0.64)$ & $3.00(0.83)$ \\
\hline $\mathrm{FEV}_{1}(\mathrm{~L})$ & $1.59(0.52)$ & $1.62(0.66)$ \\
\hline $\mathrm{FEV}_{1}, \%$ predicted & $62.0(19.5)$ & $61.1(18.7)$ \\
\hline $\mathrm{FEV}_{1} / \mathrm{FVC}(\%)$ & $54.5(13.1)$ & $54.1(14.1)$ \\
\hline Inspiratory capacity (L) & $1.97(0.47)$ & $2.00(0.59)$ \\
\hline MMF (L/s) & $0.73(0.63)$ & $0.75(0.47)$ \\
\hline $\mathrm{V}_{50}(\mathrm{~L} / \mathrm{s})$ & $1.07(0.84)$ & $1.09(0.62)$ \\
\hline $\mathrm{V}_{25}(\mathrm{~L} / \mathrm{s})$ & $0.31(0.27)$ & $0.31(0.16)$ \\
\hline CAT & II.2(6.6) & I I.0 (7.4) \\
\hline
\end{tabular}

Note: Data are expressed as number (\%) or mean (SD).

Abbreviations: COPD, chronic obstructive pulmonary disease; GOLD, Global initiative for chronic Obstructive Lung Disease; FVC, forced vital capacity; FEV, forced expiratory volume in I second; MMF, maximum midexpiratory flow rate; $\mathrm{V}_{55}$, maximum expiratory flow rate at $50 \% \mathrm{FVC} ; \mathrm{V}_{25}$, maximum expiratory flow rate at $25 \%$ FVC; CAT, COPD assessment test; SD, standard deviation.

former or current smokers with a mean smoking history of 61.2 pack-years. The proportions of the GOLD classification stages according to airflow limitation severity were $24.4 \%$ in stage I, $41.5 \%$ in stage II, and $34.1 \%$ in stage III. No patients in stage IV were included. Most patients (81.7\%) had already received tiotropium or LABA treatment and 14 patients had been treated with inhaled corticosteroid before enrollment in the study. There were no significant differences between the tiotropium and indacaterol treatment groups in the clinical features ( $P \geq 0.05$ for each comparison; Tables 1 and 2). The mean $\mathrm{FVC}, \mathrm{FEV}_{1}$, and inspiratory capacity in the indacaterol treatment group were $2.90 \mathrm{~L}, 1.59 \mathrm{~L}$, and $1.97 \mathrm{~L}$, respectively, and did not differ from those in the tiotropium treatment group $(3.00 \mathrm{~L}, 1.62 \mathrm{~L}$, and $2.00 \mathrm{~L}$, respectively, $P \geq 0.05$ for each comparison). The CAT scores in the indacaterol treatment group and tiotropium treatment group were 11.2 and 11.0 , respectively $(P=0.686)$.

\section{Lung function and COPD control}

After 8 weeks of treatment with indacaterol or tiotropium, the pulmonary function test results were improved. In the indacaterol treatment group, $\mathrm{FVC}, \mathrm{FEV}_{1}$, percentage of predicted $\mathrm{FEV}_{1}, \mathrm{MMF}, \mathrm{V}_{50}$, and $\mathrm{V}_{25}$ were significantly 
Table 2 Pulmonary function and COPD assessment scores before and after indacaterol and tiotropium treatment for 8 weeks

\begin{tabular}{|c|c|c|c|c|c|c|c|}
\hline & \multicolumn{3}{|c|}{ Indacaterol treatment } & \multicolumn{3}{|c|}{ Tiotropium treatment } & \multirow{2}{*}{$\begin{array}{l}\text { Comparison between } \\
\text { treatment }^{\dagger}\end{array}$} \\
\hline & Baseline & After & Change & Baseline & After & Change & \\
\hline FVC (L) & $2.90(0.64)$ & $3.06(0.61)^{*}$ & $0.13(0.26)$ & $3.00(0.83)$ & $3.07(0.78)$ & $0.07(0.3 \mathrm{I})$ & 0.363 \\
\hline $\mathrm{FEV}_{1}(\mathrm{~L})$ & $1.59(0.52)$ & $1.76(0.53)^{*}$ & $0.16(0.19)$ & $1.62(0.66)$ & $1.70(0.67)^{*}$ & $0.08(0.18)$ & $0.04 I^{* *}$ \\
\hline $\mathrm{FEV}_{1}, \%$ predicted & $62.0(19.5)$ & $68.6(18.3)^{*}$ & $7.05(8.00)$ & $61.1(18.7)$ & $63.6(19.2)^{*}$ & $2.56(7.64)$ & $0.013 * *$ \\
\hline $\mathrm{FEV}_{\mathrm{I}} / \mathrm{FVC}(\%)$ & $54.5(13.1)$ & $57.9(13.3)^{*}$ & $3.43(4.55)$ & $54.1(14.1)$ & $55.7(14.1)$ & $1.54(7.36)$ & 0.156 \\
\hline Inspiratory capacity (L) & $1.97(0.47)$ & $2.07(0.48)$ & $0.06(0.24)$ & $2.00(0.59)$ & $1.96(0.58)$ & $-0.04(0.38)$ & 0.154 \\
\hline MMF (L/s) & $0.73(0.63)$ & $0.89(0.72)^{*}$ & $0.15(0.27)$ & $0.75(0.47)$ & $0.88(0.63)$ & $0.13(0.45)$ & 0.732 \\
\hline $\mathrm{V}_{50}(\mathrm{~L} / \mathrm{s})$ & $\mathrm{I} .07(0.84)$ & $1.30(0.91)^{*}$ & $0.23(0.33)$ & $1.09(0.62)$ & $1.20(0.78)$ & $0.11(0.34)$ & 0.144 \\
\hline $\mathrm{V}_{25}(\mathrm{~L} / \mathrm{s})$ & $0.31(0.27)$ & $0.36(0.32)^{*}$ & $0.05(0.13)$ & $0.31(0.16)$ & $0.33(0.18)$ & $0.02(0.10)$ & 0.309 \\
\hline CAT & II.2(6.6) & $7.5(5.6)^{*}$ & $-3.54(4.67)$ & II $.0(7.4)$ & $10.0(7.3)$ & $-0.90(3.63)$ & $0.008 * *$ \\
\hline
\end{tabular}

Notes: Values are expressed as mean (SD). ${ }^{\dagger}$ Comparison of changes in indacaterol treatment and tiotropium treatment. $* P<0.05$ compared with baseline. $* * P<0.05$, significant difference between changes with indacaterol treatment and tiotropium treatment.

Abbreviations: COPD, chronic obstructive pulmonary disease; FVC, forced vital capacity; FEV , forced expiratory volume in I second; MMF, maximum midexpiratory flow rate; $\mathrm{V}_{50}$, maximum expiratory flow rate at $50 \%$ FVC; $\mathrm{V}_{25}$, maximum expiratory flow rate at $25 \% \mathrm{FVC}$; CAT, COPD assessment test; SD, standard deviation.

increased. In the tiotropium treatment group, $\mathrm{FEV}_{1}$ and percent predicted $\mathrm{FEV}_{1}$ were increased. There were no inspiratory capacity changes in the indacaterol treatment group or tiotropium treatment group (Table 2). Compared with the differences between the baseline and posttreatment values in the tiotropium treatment group, the indacaterol treatment group showed significant larger increases in $\mathrm{FEV}_{1}$ and percent predicted $\mathrm{FEV}_{1}(P=0.041$ and $P=0.013$, respectively). The CAT score was significantly decreased from $11.2 \pm 6.6$ to $7.4 \pm 5.6$ in the indacaterol treatment group $(P<0.001)$. However, the CAT scores were nearly equal between baseline

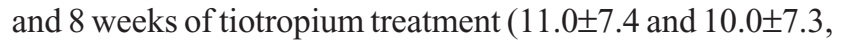
respectively). Compared with tiotropium, 8 weeks of treatment with indacaterol significantly improved the CAT score $(P=0.008)$. When the patients were divided using an increase of two points in the CAT score as the accepted minimum clinically important difference, ${ }^{24} 23$ and 13 patients showed CAT improvements of more than two points in the indacaterol treatment group and tiotropium treatment group, respectively.

\section{Forced oscillation technique}

The respiratory resistance and respiratory reactance at wholebreath, inspiratory, and expiratory phases and the expiratoryinspiratory difference are summarized in Table 3. At the whole-breath phase, R5, Fres, and ALX were decreased and X5 was increased with statistical significance after 8 weeks of indacaterol treatment. In addition, R5-R20 at the inspiratory phase was decreased in the indacaterol treatment group. At the expiratory phase, reactance parameters improved in the indacaterol treatment group. Similar FOT changes were observed in the tiotropium treatment group, in that R5, Fres, and ALX were decreased and X5 was increased at the whole-breath phase. However, there were no differences in these FOT changes between the indacaterol treatment group and tiotropium treatment group. Regarding the differences between the expiratory and inspiratory phases, the respiratory reactance parameters were significantly changed in both the indacaterol treatment and tiotropium treatment groups. $\Delta \mathrm{X} 5$ with indacaterol treatment and tiotropium treatment were 0.36 and 0.19 , respectively, with no significant difference $(P=0.465)$. In the comparisons with the changes in $\mathrm{FEV}_{1}$, the baseline R5 and X5 values at the whole-breath phase showed significant correlations $(r=0.326, P=0.046$ and $r=-0.330, P=0.043$, respectively) only in the indacaterol treatment group. Next, we evaluated the relationships between the changes in $\mathrm{FEV}_{1}$ and the FOT parameters after the treatments. The changes in R5, R5-R20, X5, Fres, and ALX were significantly correlated with the changes in $\mathrm{FEV}_{1}$ (R5: $r=-0.336, P=0.040$; R5-R20: $r=-0.345$, $P=0.034$; X5: $r=0.363, P=0.025$; Fres: $r=-0.393, P=0.014$; ALX: $r=-0.471, P=0.009$ ) only in the indacaterol treatment group. Conversely, in the tiotropium treatment group, there were no correlations between the changes in $\mathrm{FEV}_{1}$ and the FOT parameters.

\section{Discussion}

This study was designed to investigate the efficacies of only indacaterol and tiotropium monotherapies based on the airflow limitation, the impact on health status, and respiratory impedance in patients with mild-to-severe COPD. Both indacaterol and tiotropium improved the pulmonary function. Compared with tiotropium, indacaterol significantly increased $\mathrm{FEV}_{1}$ and percent predicted $\mathrm{FEV}_{1}$ and improved symptoms. We used a multifrequency FOT to assess the changes in respiratory resistance and respiratory reactance, 
Table 3 Respiratory resistance and respiratory reactance at whole-breath, inspiratory, and expiratory phases, and differences between inspiratory and expiratory phases

\begin{tabular}{|c|c|c|c|c|c|c|c|}
\hline & \multicolumn{3}{|l|}{ Indacaterol } & \multicolumn{3}{|l|}{ Tiotropium } & \multirow{2}{*}{$\begin{array}{l}\text { Comparison } \\
\text { between } \\
\text { treatment** }\end{array}$} \\
\hline & Baseline & After & Change & Baseline & After & Change & \\
\hline \multicolumn{8}{|c|}{ Whole-breath } \\
\hline R5 & $3.38(1.20)$ & $3.14(1.05)^{*}$ & $-0.21(1.01)$ & $3.44(\mathrm{I} .3 \mathrm{I})$ & $2.97(1.18)^{*}$ & $-0.46(1.08)$ & 0.280 \\
\hline $\mathrm{R} 20$ & $2.67(0.79)$ & $2.56(0.77)$ & $-0.07(0.66)$ & $2.66(0.85)$ & $2.34(0.82)^{*}$ & $-0.32(0.79)$ & 0.131 \\
\hline R5-R20 & $0.70(0.54)$ & $0.59(0.45)$ & $-0.12(0.58)$ & $0.76(0.55)$ & $0.64(0.50)$ & $-0.13(0.46)$ & 0.957 \\
\hline$\times 5$ & $-1.24(1.14)$ & $-0.74(0.59)^{*}$ & $0.43(0.72)$ & $-1.49(1.50)$ & $-0.99(\mathrm{I} . \mathrm{II})^{*}$ & $0.50(1.00)$ & 0.711 \\
\hline Fres & I 3.78 (5.99) & $10.84(4.39)^{*}$ & $-2.86(4.89)$ & $14.80(6.75)$ & $12.22(5.68)^{*}$ & $-2.58(4.13)$ & 0.782 \\
\hline$A L X$ & $9.15(10.27)$ & $4.44(5.22)^{*}$ & $-4.30(7.50)$ & $12.34(\mid 6.21)$ & $7.13(9.72)^{*}$ & $-5.22(\mathrm{I} I .23)$ & 0.673 \\
\hline \multicolumn{8}{|c|}{ Expiratory phase } \\
\hline $\mathrm{R} 5$ & $3.68(1.35)$ & $3.53(1.25)$ & $-0.13(1.20)$ & $3.77(\mathrm{I} .4 \mathrm{I})$ & $2.30(1.38)^{*}$ & $-0.48(1.29)$ & 0.220 \\
\hline $\mathrm{R} 20$ & $2.8 \mathrm{I}(0.86)$ & $2.75(0.87)$ & $-0.02(0.7 I)$ & $2.82(0.91)$ & $2.48(0.87)^{*}$ & $-0.34(0.85)$ & 0.077 \\
\hline R5-R20 & $0.87(0.65)$ & $0.78(0.58)$ & $-0.11(0.73)$ & $0.94(0.62)$ & $0.81(0.70)$ & $-0.13(0.68)$ & 0.878 \\
\hline$\times 5$ & $-1.5 \mid(1.56)$ & $-0.85(0.82)^{*}$ & $0.60(1.06)$ & $-1.98(2.33)$ & $-1.24(1.46)^{*}$ & $0.74(1.88)$ & 0.682 \\
\hline Fres & $14.9 \mid(7.02)$ & I I. $33(5.40)^{*}$ & $-3.52(5.80)$ & $16.35(8.10)$ & $13.18(7.03)^{*}$ & $-3.17(5.20)$ & 0.772 \\
\hline$A L X$ & $12.13(14.69)$ & $5.67(7.78)^{*}$ & $-6.06(11.05)$ & $17.19(25.14)$ & $10.68(14.96)^{*}$ & $-6.5 \mathrm{I}(\mathrm{I} 7.99)$ & 0.893 \\
\hline \multicolumn{8}{|c|}{ Inspiratory phase } \\
\hline R5 & $3.09(0.76)$ & $2.76(0.95)^{*}$ & $-0.28(0.88)$ & 3.09 (1.28) & $2.65(1.10)^{*}$ & $-0.45(1.01)$ & 0.451 \\
\hline $\mathrm{R} 20$ & $2.56(0.76)$ & $2.37(0.73)$ & $-0.15(0.59)$ & $2.48(0.85)$ & $2.19(0.8 \mathrm{I})^{*}$ & $-0.29(0.79)$ & 0.380 \\
\hline $\mathrm{R} 5-\mathrm{R} 20$ & $0.53(0.47)$ & $0.38(0.36)^{*}$ & $-0.15(0.47)$ & $0.61(0.52)$ & $0.46(0.45)^{*}$ & $-0.15(0.40)$ & 0.986 \\
\hline$\times 5$ & $-0.94(0.78)$ & $-0.64(0.42)^{*}$ & $0.23(0.46)$ & $-1.00(0.76)$ & $-0.56(1.12)^{*}$ & $0.44(1.05)$ & 0.262 \\
\hline Fres & $12.64(5.23)$ & $10.04(3.22)^{*}$ & $-2.50(4.26)$ & $13.35(5.85)$ & $11.27(4.62)^{*}$ & $-2.08(3.63)$ & 0.634 \\
\hline ALX & $6.08(6.46)$ & $3.19(3.06)^{*}$ & $-2.46(4.32)$ & $6.97(7.8 \mathrm{I})$ & $3.47(7.57)^{*}$ & $-3.49(8.08)$ & 0.486 \\
\hline \multicolumn{8}{|c|}{ Differences between inspiratory and expiratory phases } \\
\hline R5 & $0.59(0.64)$ & $0.76(0.72)$ & $0.15(0.60)$ & $0.68(0.66)$ & $0.64(0.78)^{*}$ & $-0.03(0.86)$ & 0.279 \\
\hline $\mathrm{R} 20$ & $0.24(0.42)$ & $0.38(0.46)^{*}$ & $0.13(0.36)$ & $0.33(0.40)$ & $0.30(0.36)^{*}$ & $-0.03(0.40)$ & 0.062 \\
\hline R5-R20 & $0.34(0.33)$ & $0.39(0.36)$ & $0.02(0.37)$ & $0.34(0.4 I)$ & $0.37(0.57)$ & $0.03(0.6 \mathrm{I})$ & 0.942 \\
\hline$\times 5$ & $-0.55(0.97)$ & $-0.20(0.56)^{*}$ & $0.36(0.78)$ & $-0.97(1.75)$ & $-0.77(1.66)^{*}$ & $0.19(1.72)$ & 0.597 \\
\hline Fres & $2.27(3.11)$ & $1.29(3.44)^{*}$ & $-1.02(2.97)$ & $2.90(3.73)$ & $1.91(3.49)^{*}$ & $-1.00(3.33)$ & 0.968 \\
\hline$A L X$ & $5.96(9.82)$ & $2.50(5.56)^{*}$ & $-3.48(7.70)$ & $10.48(19.61)$ & $7.32(14.05)^{*}$ & $-3.17(16.17)$ & 0.913 \\
\hline
\end{tabular}

Notes: $* P<0.05$ compared with baseline. ${ }^{* *}$ Comparison of changes in indacaterol treatment and tiotropium treatment. Values are expressed as mean (SD).

Abbreviations: R5, resistance at $5 \mathrm{~Hz}$; R20, resistance at $20 \mathrm{~Hz}$; X5, reactance index, reactance at $5 \mathrm{~Hz}$; Fres, resonant frequency; ALX, low-frequency reactance area; SD, standard deviation.

and found that indacaterol and tiotropium predominantly improved the reactance components. There was no difference in changes of respiratory resistance and respiratory reactance parameters between the indacaterol and tiotropium treatment groups. These results suggest that indacaterol is an effective bronchodilator for COPD with distinct properties to tiotropium.

It has been recognized that indacaterol has at least noninferior effects on FEV 1 compared to tiotropium. ${ }^{25-28}$ In the present study, patients with indacaterol treatment showed greater improvement in their airflow limitation. The mean trough $\mathrm{FEV}_{1}$ increased by $165 \mathrm{~mL}$ in the indacaterol treatment group, and was equivalent to or slightly higher than the values obtained in previous studies. ${ }^{26,27}$ Conversely, tiotropium treatment induced an $80 \mathrm{~mL}$ increase in $\mathrm{FEV}_{1}$. The difference in improvement in $\mathrm{FEV}_{1}$ between the indacaterol and tiotropium treatment groups can be attributed to several factors. First, bronchodilators dilate the airways with various potencies, ${ }^{1,2}$ and the effects of indacaterol and tiotropium may differ according to the severity of COPD. Buhl et $\mathrm{a}^{26}$ speculated that indacaterol was superior to tiotropium in moderate-or-less severe COPD patients in a subgroup analysis. In the present study, more than half of the patients had mild-and-moderate COPD and few patients had experienced exacerbation within the previous year; this may influence the greater improvement in $\mathrm{FEV}_{1}$ in the indacaterol treatment group. Second, we observed the effects of the two bronchodilators during 8 weeks of treatment after a 2 -week washout period. Although this administration period was sufficient to exert the maximal effects, the more rapid bronchodilation induced by indacaterol may contribute to the improvement of airflow limitation. ${ }^{14}$ In addition, we withdrew all long-acting bronchodilators other than tiotropium and indacaterol, methylxanthine, and corticosteroids and compared only tiotropium and indacaterol monotherapies in patients with COPD. In previous studies comparing 
indacaterol and tiotropium, ${ }^{25,26,28}$ about half of the patients included were receiving inhaled corticosteroids.

We assessed the effects of indacaterol and tiotropium on respiratory impedance using a new multifrequency FOT device, MostGraph-01. MostGraph-01 has three-dimensional color images and an added time axis to help visualize the respiratory cycle dependence. It has been reported that MostGraph-01 can assess the level of airflow limitation and bronchial reversibility in patients with asthma. ${ }^{29,30}$ Similar to other FOT devices, such as the impulse oscillation system, MostGraph-01 can measure respiratory impedance at different frequencies in a noninvasive manner. Resistances are indices of airway caliber. Increased resistance in the small airways contributes to the airflow limitation in COPD. ${ }^{31,32}$ As an imaginary part, reactance is supposed to reflect the elastic and inertial properties of the lung. ${ }^{4}$ Using an impulse oscillation system, Abe et a ${ }^{19}$ showed that treatment with tiotropium and another $\beta_{2}$-agonist, tulobuterol, improved the resistance components R5 and R5-R20 and reactance indices X5 and ALX. In the present study, R5, X5, Fres, and ALX were significantly changed by treatment with indacaterol and tiotropium. Respiratory reactance improved markedly with treatment not only at the whole-breath phase, but also at the inspiratory and expiratory phases. Although the meaning of the observations that bronchodilators predominantly improved reactance components remains unclear, reactance was reported to be more informative than resistance in explaining the changes in respiratory mechanics and airflow limitation severity in COPD. ${ }^{16,18}$ These results confirmed that the FOT can measure changes in response to therapy in a sensitive manner., ${ }^{4,7,8}$

It is known that bronchodilators increase airway diameters, decrease airway resistance, ${ }^{4}$ and make the pattern of airway obstruction more homogeneous in COPD patients. ${ }^{17}$ The airway is broadly divided into two components: large and small airways. Although not well established, several parameters of spirometry and the FOT are considered in the assessment of physiological changes in the large and small airways separately. ${ }^{19}$ Among these spirometric parameters, $\mathrm{FEV}_{1}$ is not well suited to assess the abnormalities in the small airways $^{31}$ and is characterized as a large-airway parameter. ${ }^{19}$ FVC and MMF are used as parameters in the assessment of small-airway function, ${ }^{28}$ but the latter is influenced by large-airway obstruction and volume changes in patients with obstructive pulmonary diseases. ${ }^{7,27}$ Among FOT indices, R5 is considered as a marker of total resistance ${ }^{20}$ or peripheral airway obstruction. ${ }^{7,18}$ With respect to reactance, Borrill et al ${ }^{7,8}$ showed that changes in X5 and Fres were related to small-airway bronchodilation, causing a decrease in hyperinflation and improvement in lung compliance. The phase III slope of the nitrogen $\left(\mathrm{N}_{2}\right)$ washout curve in the single-breath washout test (delta $\mathrm{N}_{2}$ ) is sensitive and the preferred small-airway index. ${ }^{31}$ Mikamo et a ${ }^{133}$ found that Fres was an independent predictor of delta $\mathrm{N}_{2}$. In the present study, there were no differences in the changes in impedance parameters reflecting the small airways between the indacaterol and tiotropium treatment groups. Conversely, indacaterol treatment induced significantly larger increases in $\mathrm{FEV}_{1}$ and percent predicted $\mathrm{FEV}_{1}$ than did tiotropium treatment. In terms of spirometric and FOT parameters, our results may suggest that indacaterol provides greater bronchodilation in the large airways and that indacaterol and tiotropium have equivalent effects on small-airway bronchodilation. Because the vagus nerve mainly innervates the large airways and there is no vagal innervation in the small airways, there is a view that anticholinergic drugs are relatively effective in the central airways. ${ }^{34}$ However, muscarinic receptors are located in all airways and those in the small airways are activated by extraneuronal acetylcholine, which enables anticholinergic agents to bronchodilate in both the large and small airways. ${ }^{35,36}$ Although the differences in potency and receptor binding affinity between indacaterol and tiotropium may induce the different bronchodilation in the large airways, more studies are needed to clarify the underlying mechanism.

Because FOT parameters may provide complementary information to spirometry, ${ }^{7}$ the relationships between FOT and preexisting parameters of airflow limitation and inflammation have been examined. Kolsum et al ${ }^{18}$ estimated the relationships between FOT parameters and $\mathrm{FEV}_{1}$ in 94 COPD patients with a mean percent predicted $\mathrm{FEV}_{1}$ of $57.9 \%$ for 1 year. They found that R5, X5, and Fres were significantly associated with $\mathrm{FEV}_{1}$. In particular, $\mathrm{X} 5$ had the strongest association with $\mathrm{FEV}_{1}$ and sequential changes in $\mathrm{X} 5$ were significantly related to $\mathrm{FEV}_{1}$ changes over 1 year. In the present study, the changes in $\mathrm{FEV}_{1}$ were significantly correlated with the changes in R5, R5-R20, X5, Fres, and ALX at the whole-breath phase in the indacaterol treatment group. Conversely, in the tiotropium treatment group, there were no correlations between the changes in $\mathrm{FEV}_{1}$ and the FOT parameters. For the parameters reflecting inflammation, Shirai et $\mathrm{al}^{23}$ showed that differences of X5, Fres, and ALX between the expiratory and inspiratory phases were correlated with the alveolar nitric oxide concentration in patients with asthma. Williamson et $\mathrm{al}^{20}$ suggested that the value of R5-R20 was correlated with the corrected alveolar nitric oxide concentration in COPD patients. Spirometry and the 
FOT represent different aspects of respiratory physiology. The use of the FOT may enable the assessment of the effects of bronchodilators other than FEV-indicated bronchodilation. Through investigations of the relationships with preexisting parameters, the significance of the FOT in the clinical setting will be increasingly clarified.

There are limitations of the present study. First, we withdrew all bronchodilators including tiotropium and LABAs for more than 2 weeks and performed a prospective randomized trial to evaluate the efficacies of indacaterol and tiotropium monotherapies. Unfortunately, however, it was not a blinded study. Second, although indacaterol showed good efficacy on symptoms and airflow limitation, a long-term follow-up period is necessary to assess the effects on exacerbation.

In conclusion, indacaterol significantly improved the airflow limitation and symptoms. For respiratory impedance, indacaterol and tiotropium improved the FOT parameters to similar extents. Both indacaterol and tiotropium enable oncedaily administration, which can improve patient adherence with therapy, and monotherapy with these bronchodilators is effective for patients with COPD.

\section{Acknowledgment}

No financial support was provided for this study.

\section{Disclosure}

The authors declare no actual or potential conflicts of interest in this work.

\section{References}

1. Global Initiative for Chronic Obstructive Lung Disease. Global strategy for the diagnosis, management, and prevention of chronic obstructive lung disease. Available from: http://www.goldcopd.org/guidelines-globalstrategy-for-diagnosis-management.html. Accessed May 20, 2014.

2. Rabe KF, Hurd S, Anzueto A, et al; Global Initiative for Chronic Obstructive Lung Disease. Global strategy for the diagnosis, management, and prevention of chronic obstructive pulmonary disease: GOLD executive summary. Am J Respir Crit Care Med. 2007;176(6):532-555.

3. Cazzola M, MacNee W, Martinez FJ, et al; American Thoracic Society, European Respiratory Society Task Force on Outcomes of COPD. Outcomes for COPD pharmacological trials: from lung function to biomarkers. Eur Respir J. 2008;31(2):416-469.

4. Oostveen E, MacLeod D, Lorino H, et al; ERS Task Force on Respiratory Impedance Measurements. The forced oscillation technique in clinical practice: methodology, recommendations and future developments. Eur Respir J. 2003;22(6):1026-1041.

5. Paredi P, Goldman M, Alamen A, et al. Comparison of inspiratory and expiratory resistance and reactance in patients with asthma and chronic obstructive pulmonary disease. Thorax. 2010;65(3):263-267.

6. Mori K, Shirai T, Mikamo M, et al. Colored 3-dimensional analyses of respiratory resistance and reactance in COPD and asthma. COPD. 2011; $8(6): 456-463$

7. Borrill ZL, Houghton CM, Woodcock AA, Vestbo J, Singh D. Measuring bronchodilation in COPD clinical trials. Br J Clin Pharmacol. 2005; 59(4):379-384.
8. Borrill ZL, Houghton CM, Tal-Singer R, et al. The use of plethysmography and oscillometry to compare long-acting bronchodilators in patients with COPD. Br J Clin Pharmacol. 2008;65(2):244-252.

9. Hellinckx J, Cauberghs M, De Boeck K, Demedts M. Evaluation of impulse oscillation system: comparison with forced oscillation technique and body plethysmography. Eur Respir J. 2001;18(3):564-570.

10. Kurosawa H, Ohishi J, Shimizu Y, et al. A new method to assess lung volume dependency of respiratory system resistance using forced oscillation. Am J Respir Crit Care Med. 2010;181:A1240.

11. van Noord JA, Bantje TA, Eland ME, Korducki L, Cornelissen PJ. A randomised controlled comparison of tiotropium and ipratropium in the treatment of chronic obstructive pulmonary disease. The Dutch Tiotropium Study Group. Thorax. 2000;55(4):289-294.

12. Tashkin DP, Celli B, Senn S, et al; UPLIFT Study Investigators. A 4-year trial of tiotropium in chronic obstructive pulmonary disease. N Engl J Med. 2008;359(15):1543-1554.

13. Sharafkhaneh A, Mattewal AS, Abraham VM, Dronavalli G, Hanania NA. Budesonide/formoterol combination in COPD: a US perspective. Int J Chron Obstruct Pulmon Dis. 2010;5:357-366.

14. Vogelmeier C, Ramos-Barbon D, Jack D, et al; INTIME Study Investigators (INdacaterol \& TIotropium: Measuring Efficacy). Indacaterol provides 24-hour bronchodilation in COPD: a placebo-controlled blinded comparison with tiotropium. Respir Res. 2010;11:135.

15. Dahl R, Chung KF, Buhl R, et al; INVOLVE (INdacaterol: Value in COPD: Longer Term Validation of Efficacy and Safety) Study Investigators. Efficacy of a new once-daily long-acting inhaled beta2-agonist indacaterol versus twice-daily formoterol in COPD. Thorax. 2010;65(6): 473-479.

16. Di Mango AM, Lopes AJ, Jansen JM, Melo PL. Changes in respiratory mechanics with increasing degrees of airway obstruction in COPD: detection by forced oscillation technique. Respir Med. 2006; 100(3):399-410.

17. Dellaca RL, Pompilio PP, Walker PP, Duffy N, Pedotti A, Calverley PM. Effect of bronchodilation on expiratory flow limitation and resting lung mechanics in COPD. Eur Respir J. 2009;33(6):1329-1337.

18. Kolsum U, Borrill Z, Roy K, et al. Impulse oscillometry in COPD: identification of measurements related to airway obstruction, airway conductance and lung volumes. Respir Med. 2009;103(1):136-143.

19. Abe T, Setoguchi Y, Kono Y, et al. Effects of inhaled tiotropium plus transdermal tulobuterol versus tiotropium alone on impulse oscillation system (IOS)-assessed measures of peripheral airway resistance and reactance, lung function and quality of life in patients with COPD: a randomized crossover study. Pulm Pharmacol Ther. 2011;24(5): $617-624$.

20. Williamson PA, Clearie K, Menzies D, Vaidyanathan S, Lipworth BJ. Assessment of small-airways disease using alveolar nitric oxide and impulse oscillometry in asthma and COPD. Lung. 2011;189(2): 121-129.

21. Japanese Respiratory Society. Guidelines of Respiratory Function Tests: Spirometry, Flow-Volume Curve, and Diffusion Capacity of the Lung. Tokyo: Japanese Respiratory Society; 2004. [in Japanese].

22. Mori K, Shirai T, Mikamo M, et al. Respiratory mechanics measured by forced oscillation technique in combined pulmonary fibrosis and emphysema. Respir Physiol Neurobiol. 2013;185(2):235-240.

23. Shirai T, Mori K, Mikamo M, et al. Respiratory mechanics and peripheral airway inflammation and dysfunction in asthma. Clin Exp Allergy. 2013;43(5):521-526.

24. Kon SS, Canavan JL, Jones SE, et al. Minimum clinically important difference for the COPD Assessment Test: a prospective analysis. Lancet Respir Med. 2014;2(3):195-203.

25. Donohue JF, Fogarty C, Lötvall J, et al; INHANCE Study Investigators. Once-daily bronchodilators for chronic obstructive pulmonary disease: indacaterol versus tiotropium. Am J Respir Crit Care Med. 2010;182(2): $155-162$.

26. Buhl R, Dunn LJ, Disdier C, et al; INTENSITY Study Investigators. Blinded 12-week comparison of once-daily indacaterol and tiotropium in COPD. Eur Respir J. 2011;38(4):797-803. 
27. Cope S, Donohue JF, Jansen JP, et al. Comparative efficacy of longacting bronchodilators for COPD - a network meta-analysis. Respir Res. 2013;14(1):100.

28. Decramer ML, Chapman KR, Dahl R, et al; INVIGORATE Investigators. Once-daily indacaterol versus tiotropium for patients with severe chronic obstructive pulmonary disease (INVIGORATE): a randomised, blinded, parallel-group study. Lancet Respir Med. 2013;1(7): 524-533.

29. Tsuburai T, Suzuki S, Tsurikisawa N, et al. Use of forced oscillation technique to detect airflow limitations in adult Japanese asthmatics. Arerugi. 2012;61:184-193.

30. Murakami K, Habukawa C, Kurosawa H, Takemura T. Evaluation of airway responsiveness using colored three-dimensional analyses of a new forced oscillation technique in controlled asthmatic and nonasthmatic children. Respir Investig. 2014;52:57-64.

31. Contoli M, Bousquet J, Fabbri LM, et al. The small airways and distal lung compartment in asthma and COPD: a time for reappraisal. Allergy. 2010;65(2):141-151.
32. Sturton G, Persson C, Barnes PJ. Small airways: an important but neglected target in the treatment of obstructive airway diseases. Trends Pharmacol Sci. 2008;29(7):340-345.

33. Mikamo M, Shirai T, Mori K, et al. Predictors of phase III slope of nitrogen single-breath washout in COPD. Respir Physiol Neurobiol. 2013; 189(1):42-46.

34. Rennard SI. Combination bronchodilator therapy in COPD. Chest. 1995;107(5):171S-175S

35. Barnes PJ. Distribution of receptor targets in the lung. Proc Am Thorac Soc. 2004;1(4):345-351.

36. Sethi S, Cote C. Bronchodilator combination therapy for the treatment of chronic obstructive pulmonary disease. Curr Clin Pharmacol. 2011; 6(1):48-61.

\section{Publish your work in this journal}

The International Journal of COPD is an international, peer-reviewed journal of therapeutics and pharmacology focusing on concise rapid reporting of clinical studies and reviews in COPD. Special focus is given to the pathophysiological processes underlying the disease, intervention programs, patient focused education, and self management protocols.

\section{Dovepress}

This journal is indexed on PubMed Central, MedLine and CAS. The manuscript management system is completely online and includes a very quick and fair peer-review system, which is all easy to use. Visit http://www.dovepress.com/testimonials.php to read real quotes from published authors. 